\title{
Photocatalytic Functionalization of Alkenes with a Metal-Organic Layer Containing Eosin Y and Iron
}

Polymer-Supported

Synthesis

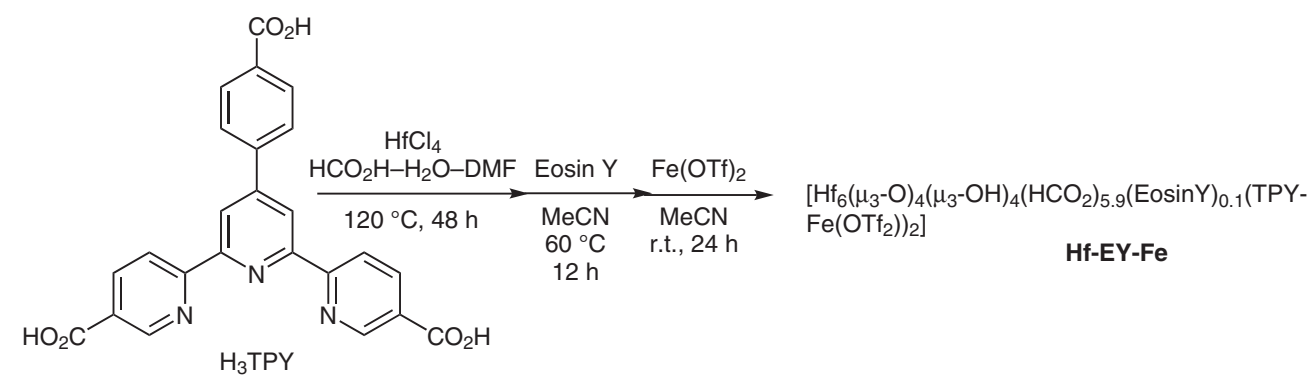

\section{Key words}

photocatalysis

alkenes

trifluoromethylation

\section{Synfact is of the Month}

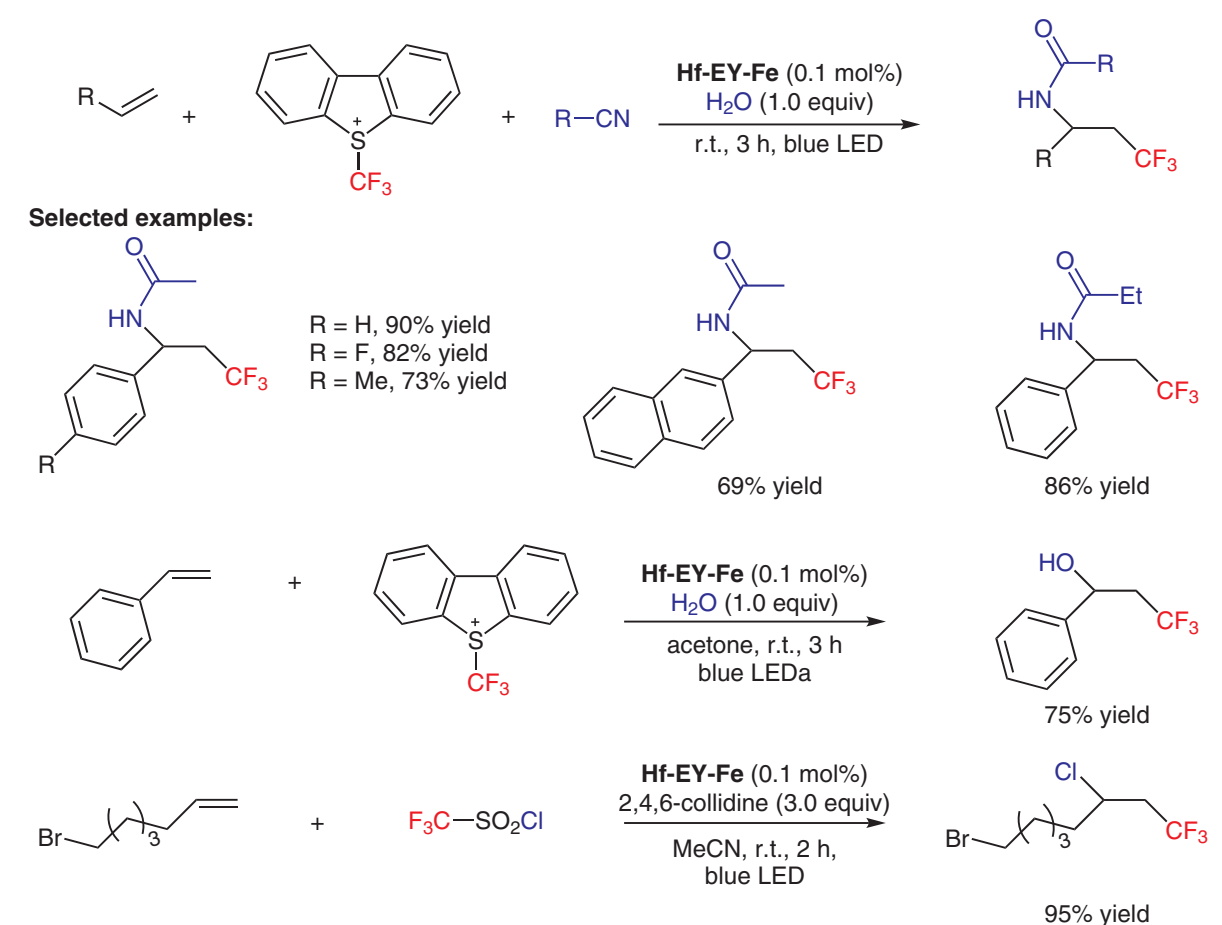

Significance: A metal-organic layer (MOL) containing eosin $\mathrm{Y}$ and Fe-TPY ligands (Hf-EY-Fe), prepared according to equation 1 , catalyzed the trifluoromethylative amination (eq. 2), hydroxylation (eq. 3 ), or chlorination (eq. 4) of alkenes to give the corresponding products in yields of up to $95 \%$.
Comment: Hf-EY-Fe was characterized by means of ICP-MS, TEM, AFM, HRTEM, PXRD, UV-Vis, fluorescence, XANES, XPS, and EXAFS analyses. In the trifluoromethylative chlorination of 7-bromohept1-ene with trifluoromethanesulfonyl chloride, the catalyst was recovered and reused four times without significant loss of its catalytic activity. 